\title{
Change technology and the implementation of automation in mental health care settings
}

\author{
ELIZABETH BYRNES and JAMES H. JOHNSON \\ Illinois Institute of Technology, Chicago, Illinois 60616
}

\begin{abstract}
The problem of clinician resistance to automated systems in mental health care delivery settings is discussed. It is argued that this resistance is a natural part of the change process. an indicator of an inadequate change strategy. The theory of change is briefly reviewed. Previous efforts to install automated systems in mental health care delivery settings are discussed in terms of change theory. Suggestions for incorporating the technology of change into the implementation process are proposed.
\end{abstract}

Technological change in mental health care delivery has been stimulated by two goals: improving patient care and reducing costs. Research reports attest that automated systems are cost effective (Klingler, Johnson, \& Williams, 1976; Klingler, Miller, Johnson, \& Williams, 1977 ) and are accepted favorably by patients (Grossman, Barnett, McGuire, \& Swedlow, 1971; Klingler et al., 1976). However, despite positive evaluation studies and strong rational arguments, computers still have failed to gain wide clinical acceptance and support.

Experience with clinical applications of computer technology has resulted in numerous research reports naming "clinician acceptance" as a critical factor underlying successful implementation (Brewer, Ameiss, Thompson, \& Wood, 1972; Dow, 1975; Graetz, 1966; Grossman et al., 1971; Hedlund, 1974; Johnson, Williams, Giannetti, Klingler, \& Nakashima, 1978; Leader \& Klein, 1977; Hedlund, Note 1). Because clinical staff members have difficulty accepting these new approaches to patient care, the effectiveness of new computer applications has been limited.

The basic contention set forth in this paper is that the successful implementation of computers in mental health requires a fundamental understanding of the factors preceding and surrounding change. In the past, psychologists have concentrated too heavily on using computer science in mental health and have too often minimized the use of psychological principles in bringing about innovative change. The need for deliberate planning for change is apparent and well documented [Human Interaction Research Institute/National Institute of Mental Health (HIRI-NIMH), 1976]. Conceptualizations and insights derived from the literature on "change and the utilization of knowledge" offer a host of alternative approaches.

Research on the topic of change has become particularly salient in the last 20 years. Between 1955 and 1975, references concerning planned change increased from 400 to over 20,000 (Davis \& Salasin, 1975). This expanding source of knowledge contains a wealth of applicable wisdom derived from observation and experience. A smaller portion of the research contains formal conceptualizations based on empirical research.

A pressing question for mental health professionals is, "How do we effectively use our knowledge and research to bring about needed improvements in conventional practice?" (HIRI-NIMH, 1976). This paper reviews the computer implementation experiences of others and discusses this research in terms of change technology. This mixture of "conventional wisdom" together with concepts from the theory of change should help build a stronger framework for future efforts to install automated innovations in the mental health field.

\section{OVERVIEW OF THE CHANGE LITERATURE}

Previous research on change technology points to a complex interaction of components affecting the implementation of an innovative system (HIRI-NIMH, 1976). For the present review and discussion, three central components are examined briefly: organizational readiness, strategies for planned change, and the issue of resistance.

\section{Organizational Readiness}

The success of a change process depends greatly on the organizations's readiness to adopt an innovation. Numerous organizational factors have been proposed that bear directly on the change process. For example, Kiresuk, Davis, and Lund (1980) name four organizational components that must be considered prior to undergoing change. Kiresuk et al. suggest that the goals, structure, climate, and personnel of an organization may singly or together serve to facilitate or hinder constructive organizational innovation.

In order to illuminate, and eventually overcome, impediments to organizational change, several writers have proposed systems models. These models seek to separate those factors important to a particular phase or phases of the change process while systematically drawing the attention of change implementers to the critical 
components prior to and during the adoption process. Three well-known models are the "A VICTORY" formulation of change factors (Davis, 1971), the "CORRECT" list of change characteristics (Glaser, 1973), and the Zaltman list of innovation attributes (Zaltman, Duncan, \& Holbek, 1973). A VICTORY and CORRECT are acronyms proposed as convenient memory devices. Each of these models uses different sets of terms; however, they are related in many instances. The interrelationships among the respective factors is illustrated in a table of integrated findings presented by the HIRI/NIMH (1976).

Only the A VICTORY model of Davis (1971) has been applied specifically to the task of evaluating an organizations's readiness to adopt innovations (Kiresuk et al., 1980). The eight categories of the A VICTORY model are abilities (available resources and abilities), values (conducive philosophy and operating style), ideas (adequate knowledge about qualities of an innovation), circumstances (other factors that prevail at the time), timing (readiness for implementation), obligation (felt need to change), resistances (organizational or individual disinclination to change), and yield (perceived benefits or payoff brought about by the change). The comprehensiveness of the A VICTORY model makes it a particularly useful technique for those intending to adopt automated systems. It can be used as a conceptual tool for extracting critical change factors and as a basis for assessing organizational readiness for change (Kiresuk et al., 1980).

\section{Strategies for Change}

The implementation of any innovative program requires the adoption of a strategy for change. This serves to outline the necessary steps of the process and provides a well-defined plan of action.

There are numerous change strategies named in the literature. Zaltman (1973) demonstrates the range in a "typology of change strategies." Kotler (1973) presents three general strategies and procedures for effecting planned change. These include the power strategy, the persuasion strategy, and the reeducative strategy. The power strategy is a tactic that seeks behavioral compliance through the selective distribution of rewards and punishments. The persuasion strategy attempts to bring about change by arguing that the proposed innovation serves the best interests of all involved. The reeducative strategy attempts to induce the desired change by altering the beliefs and/or values of the people involved. Kotler notes that these strategies are rarely used alone, and in fact, an actual change effort may combine all three.

Zaltman and Duncan (1977) explain each of the above strategies in depth. In addition, they have added one additional change tactic, a facilitative strategy. A facilitative strategy is a tactic whereby assistance is made available to aid in the implementation process.
Thus, the change process can follow several alternative core plans. However, the particular change strategy adopted should reflect the notion of how those to be changed are influenced most effectively. Each change strategy approaches the situation differently, carrying with it a different philosophy for dealing with change resistance.

\section{Resistance to Change}

Resistance is likely to occur whenever change is attempted in an organization. Forces that serve to maintain the status quo may be perceived as resisting change (Watson, 1973). From the viewpoint of an ambitious and energetic proponent of a new technology, these resistances are a pervasive obstacle to innovation (Kiresuk et al., 1980; Watson, 1973).

Zaltman and Duncan (1977) emphasize two important points to be considered when dealing with resistance. First, resistance is a healthy phenomenon and may serve as a valuable clue regarding the nature of the change process. Second, resistance may be caused by change-agent errors and thus reflects a need to reevaluate the change process.

Resistance may occur at any point in the change process. Watson (1973) suggests that a wise strategy is to perceptively analyze the nature of the resistance. He specifies two sets of resistance forces: those that operate within the individual personality, and those most clearly recognized in the social system. After outlining the sources of resistance in individuals and the social system, Watson concludes with 13 recommendations for reducing resistance that are designed to answer three questions: Who brings the change? What kind of change succeeds? How is it best done, by what procedures and in what climate?

Kiresuk et al. (1980) recommended clear, thorough, and accurate communication during implementation in order to avoid resistance stemming from confusion, lack of knowledge, and uncertainty. In situations in which change strategies are based on compulsion or coercion, resistance is best avoided by negotiating key issues and maintaining appropriate levels of staff involvement in decision making (Kiresuk et al., 1980).

In summary, resistance must be carefully analyzed at each stage of the change process. Although it may be perceived as a frustrating nuisance to the enthusiastic promoter of an innovation, resistance can be a source of valuable feedback on the nature and value of the innovation.

\section{COMPUTER TECHNOLOGY-THE PROBLEM OF CHANGE}

A review of the literature reveals only one study (Johnson et al., 1978) that applies the conceptual change principles to actual implementation of a computer system in a mental health facility. Following 3 years of 
operation, the developers of the Psychiatric Assessment Unit (PAU) at the Salt Lake City Veterans Administration Hospital and the University of Utah carried out a post hoc study using Davis' (1971) A VICTORY model of change factors. The evaluation was completed to find out if organizational preparedness for change was an issue that might relate to the relatively low level of clinician acceptance.

Staff members were administered a questionnaire to assess the organization's readiness to accept the PAU in terms of the eight A VICTORY categories. The results of this study showed that while the organization was viewed as having the abilities and resources to implement the PAU, the staff members did not feel any obligation or need to change from the existing operating mode. These results are highlighted by the negative results obtained when clinicians were asked to measure the actual use and rate the perceived value of the PAUgenerated materials. Johnson et al. (1978) concluded that their failure to communicate the rationale for the development of the PAU resulted in a lack of commitment and support for the new system. Using the A VICTORY concepts, it can be seen that too little time and energy was devoted to the organization's values, sense of obligation, and realization of yield. Furthermore, the possible resistances were not anticipated and, hence, were encountered unexpectantly. In essence, the organization was not ready for innovative change.

This retrospective analysis highlights the issues of resistance and underscores the issue of organizational readiness. However, preparing a change strategy, an important component of the change process, was completely overlooked. Johnson et al. (1978) failed to recognize that organizational readiness was something to be facilitated by a comprehensive plan of action. Instead, they focused on resistance, a prevalent symptom in unplanned change settings. Had Johnson et al. been familiar with change theory research, they would have recognized the missing link between organizational readiness and resistance.

We are not aware of any other automation programs in mental health in which there is a formal discussion or emphasis on the principles of change. Nevertheless, these implementation experiences reveal a variety of problems and a number of proposed solutions for dealing with user acceptance in the future. Using the Johnson et al. (1978) report as a guide, we will examine these programs retrospectively using the factors of change.

\section{The Missouri Standard System of Psychiatry (SSOP)}

In the mid-1960s, the Missouri Institute of Psychiatry and the Missouri Division of Mental Health began to develop and, subsequently, implement an extensive computer system to meet the dual needs of both the clinical and administrative staffs. Hedlund, Sletten, Evenson, Altman, and Cho (1977) summarize 10 years of research, development, and experience with this state-wide system. Their review of the implementation of the SSOP illuminates a number of special problems and issues that bear directly on the three central components for change discussed above.

First, there is the issue of readiness for implementation. Hedlund et al. (1977) indicate that careful planning in the form of a formal clinical and managerial systems study preceded the implementation process. However, notably absent from their discussion of readiness is attention to staff preparedness for change, a prerequisite to organizational commitment and support. This oversight became apparent when the system failed to function optimally and cost-effectively (Hedlund, Note 1; Sletten \& Hedlund, Note 2). This experience underscores a recurrent and frustrating lesson, namely, that a promising innovative idea, even when accompanied by adequate design considerations, may not be readily accepted and used.

A second issue concerns change strategies. Hedlund et al. (1977) do not formally acknowledge a change strategy for the adoption process. However, the authors do mention tactics used when initially implementing and developing the SSOP. For example, facility superintendents and business administrators were authorized to enroll in brief computer courses. This requirement, along with bimonthly project meetings during the first 2 or 3 years, reflects the coercion and persuasion strategies described by change theorists. It seems unlikely that the SSOP project staff and administration were aware of the need for a change plan that would see them through the initial system introduction and also provide solutions to problems arising later in the process. This naiveté, characteristic of those unfamiliar with change technology, is highlighted by the presence of resistance.

Resistance, in the form of marginal user acceptance, was the third issue that became a major hindrance to rapid development. User acceptance encompasses a number of complex issues, including optimal levels of standardization, available knowledge, and perceived benefits and end results (Hedlund, Note 1). In change terminology, this resistance reflects inattention to organizational goals, clinicians' values, transmission of information, and perceived yield.

It is clear from the discussion of Hedlund et al. (1977) that resistance to computers and to the process of change slowed the implementation process despite extensive efforts to involve staff members in the early conception, pilot testing, and development of each computer application. Their experience underscores the need for an approach to innovative change that serves as an aid throughout the implementation process. Of particular informative value is the presence of resistance, since it reveals problems in organizational readiness and in change strategy. In essence, resistance indicates that an implementation plan must be evaluated and revised.

\section{The Hahnemann Community Mental Health Center}

St. Clair, Siegel, Caruso, and Spivack (1976) reviewed the difficulties involved in the implementation of a 
computerized management information system. They note that there are numerous guidelines available on the design and use of systems, but no known reports that speak to the time and man power automation demands. Extensive planning preceded the implementation of this system. Nevertheless, problems and issues arose that slowed the process. Although St. Clair et al. do not deal directly with the components of creative change, the issues they address clearly reflect the process.

St. Clair et al. (1976) proposed that there are several crucial aspects for successful planning. Among these considerations are several components of organizational readiness. The first suggested requirement preceding implementation is widespread information gathering. This step requires that the core decision making personnel read the computerization literature and review the experiences of other mental health centers with automated systems. The goal of these information gathering tasks is administrative preparedness, a crucial component of organizational preparedness for change. St. Clair et al. recognize the second vital component of the planning phase to be staff preparedness. This is recognized as a much more complex task due to the variability of the staff. The steps recommended by St. Clair et al. include in-service training and an open arena for staff comments and criticisms regarding automation. In addition, two areas St. Clair et al. retrospectively recognize as important to the planning process are building a realistic time schedule and including sufficient personnel to staff the project.

The implementation process described by St. Clair et al. (1976) omits discussion of a detailed strategy for change. Nevertheless, change tactics from the reeducative, persuasive, and coercion plans are evident and reflect an eclectic approach. Initially, staff meetings and mandatory workshops were held to announce the pending automation. Once implementation was underway, the project staff were busy with programming details regarding data input and output, and hence, they were relatively unaware of growing staff resistance. Staff nonacceptance became a major problem and took the form of inattention to detail, slow performance, and open resentment. The project staff, being relatively unfamiliar with change technology, were unprepared for these resistance issues. Early in the planning phase, in-service training was aimed at emphasizing the multiple benefits of an automated system. Yet they failed to gain staff cooperation and acceptance using this persuasive logic. The project staff did not recognize this error in planning until resistance served to radically hinder the implementation process. At this point, they again tried to persuade and reason with the clinical staff in hopes of increasing their support and cooperation. When this proved futile, the administration used extensive negative feedback via fierce meetings and memos. As a consequence, the error rate dropped from 160 to 0 during this period of coercive techniques. However, a coercive strategy, when used without careful planning, can create problems as quickly as they are resolved. Staff noncompliance began again after the coercive strategy was discontinued.

In retrospect, St. Clair et al. (1976) recommended greater attention to staff resistance and morale. They suggest a comprehensive implementation plan that will reeducate clinicians on the importance and value of automated data systems. Finally, they report that effective persuasion is more likely if a system of positive reinforcements is built into the change process.

In summary, St. Clair et al. (1976) experienced many of the problems inherent in unorganized change. Project and administrative familiarity with the psychology of change would probably have allowed for a much smoother implementation process by lessening the number of unexpected problems.

\section{Hillside Medical Center}

Leader and Klein (1977) were active in the initial design and implementation of a new automated technique for preparing psychiatric case studies. Their effort led to a procedure called the Developmental and Social History (DASH). The DASH project encountered many difficulties during the change process, including repeated computer breakdowns and pervasive nonacceptance. Five years after the idea for a computerized system originated, project funds were cut and DASH came to an end. Since that time, Leader and Klein (1977) have retrospectively analyzed their implementation procedures. Their discussion of this experience shows the problems inherent in unplanned change.

Leader and Klein (1977) make clear that they, like many others who have designed innovative approaches, were "naive and ultimately self-defeating" in thinking that the rational appeal of this technological advance would be sufficient to guarantee user acceptance and administrative support. In their implementation process, organizational readiness was largely overlooked. As a result, DASH was introduced in an unsuitable attitudinal climate that was intolerant of its developmental shortcomings. There were several vital factors missing from this DASH implementation. Among those they cite are adequate funding, thorough pilot testing of the system, support from the clinical leadership, proper timing, and staff openness to innovations.

Leader and Klein's (1977) review of the implementation omits any reference to the use of change strategies. There was minimal consultation with the clinical staff regarding the development and application of the DASH system, and in turn, there was minimal clinical response to later inquiries regarding DASH's clinical usefulness. In essence, a vicious cycle of noncommunication existed. A change strategy, which consists of planned and purposive communication between the change agents and those staffing the innovative system, would have been a valuable addition to the implementation process. 
It is interesting to note that the initial creation and design of DASH came about because of a special grant and, thus, reflects the facilitative change strategy. However, this strategy was not accompanied by other tactics, such as persuasion and coercion. As a result, the withdrawal of funding led to the rapid collapse of the program. This experience underscores the necessity for an effective and durable change strategy.

Resistance was consistently evident during DASH's operation. It took the general form of user noncompliance and eventually led to the withdrawal of administrative and financial support for the DASH project. Leader and Klein (1977) now feel that resistance reflects inattention to the preparedness of their hospital for change. Recently, they have applied the A VICTORY model (Davis, 1971) to the current practices and attitudinal climate of their hospital as a prerequisite to reintroducing DASH. This is an important step toward successful implementation. However, a change strategy is needed to guide the process according to the unique characteristics of their hospital. Otherwise, resistance is likely to continue to hinder their progress.

\section{The Juvenile and Family Court Clinic}

This clinic provides predisposition assessments and recommendations to judges for juveniles (Landau \& Wilks, 1975). An automated information system was developed to meet research, administrative, and clinical needs. In reporting on their implementation experience, Landau and Wilks note that the design of this complex system was less demanding than the task of overcoming staff anxieties, apathy, and antagonism. Once again, staff resistance was a visible component of innovative change.

Landau and Wilks (1975) presented a summary of the critical implementation issues and summarized the strategies they developed to deal with these issues. They began with an organization that was ready to try a more effective method of data gathering. Both the administrative and clinical staff recognized the need for a comprehensive system.

Although Landau and Wilks (1975) did not discuss change technology directly, their approach made use of several persuasive techniques. The design and pilot testing of the system involved extensive input from the clinical staff. In addition, the clinical staff was asked to evaluate the advantage of the computer reports as compared with the previous manual reports. In this manner, the administration showed the staff the value of the computer system.

Problems arose that might have created major resistances. However, the fears of clinicians were openly discussed, and solutions were negotiated that satisfied both administrative and staff concerns. Throughout this implementation process, a persuasive strategy served to highlight and maximize the advantages of change while minimizing the fears and apprehensions so commonly associated with innovations. Resistances still appeared, but Landau and Wilks (1975) recognized the information reflected by these resistances and adapted their change plan accordingly.

\section{Other Systems}

There are numerous other implementation reports in the literature. In each case, the authors make comments about what they would do differently if they were starting over again. For these researchers, experienced with automated systems, there is a consensus about the proper conditions for implementation. This "practical wisdom" reflects factors of the three major components of change: organizational readiness, strategies for change, and overcoming resistance.

\section{Organizational Readiness}

There is a widespread agreement that implementation should begin with an overall systems study (Bennett \& Houck, 1967; Cole, Johnson, \& Williams, 1975; Glueck, 1967; Graetz, 1966; Johnson, 1980; Murray \& Klainer, 1972; Burwell \& Chavern, Note 3; Sorenson \& Hanbery, Note 4). Clinicians should be actively involved in both the systems study and the design (Bennett \& Houck, 1967; Elpers \& Chapman, 1973; Graetz, 1966; Johnson, 1980; Klein, Greist, \& VanCura, 1975; Laska, Logemann, Weinstein, \& Bank, 1970; Rosenberg \& Ericson, 1969). Finally, the computer scientists involved in the systems analysis should work closely and harmoniously with the clinical staff (Bennett \& Gruenberg, 1970; Bennett \& Houck, 1967; Dow, 1970; Burwell \& Chavern, Note 3).

\section{Strategies for Change}

Once the organization is ready for change and a systems analysis is complete, the process of installation can proceed under the direction of a change strategy. However, the experiential literature lacks references to this component of the change process. Thus, no specific strategy based on experience has been advocated for installing an automated system in the mental health area.

\section{Overcoming Resistance}

Resistance from the individual, the staff, or the organization as a whole must be attended to. Numerous tactics for overcoming clinical resistance are available in the literature, reflecting the universality of the probiem. Experienced implementers recommend a systems design that (1) acknowledges the clinicians' usual data collection habits (Grossman et al., 1971), (2) supports and removes work from the clinician (Bennett \& Gruenberg, 1970; Brewer et al., 1972; Freil, Reznikoff, \& Rosenberg, 1969; Hedlund et al., 1977; Murray \& Klainer, 1972), (3) is well documented in the form of users' manuals and training (Sorensen \& Hanbery, Note 4), (4) has well designed forms and output (Bennett \& Gruenberg, 1970; Elpers \& Chapman, 1973; Johnson et al., 1978; Klein et al., 1975), and (5) provides rapid feedback to the clinician (Bennett \& Gruenberg, 1970; Elpers \& Chapman, 1973; Sorensen \& Hanbery, Note 4). 


\section{DISCUSSION}

The experiences reviewed in this paper are only a sample of the many automation projects undertaken in the mental health field. Our summary of these experiences shows how the principles of change theory have been used in the past. Even so, there has been little attention to the accumulation of practical wisdom that offers helpful insights. We contend that successful implementation requires a change plan that integrates both the conceptual and the practical knowledge. Several important principles regarding the installation of computers in psychology follow from this position.

First, innovators must understand the change process. Project staff must be familiar with the way change affects the individual and the organization. These questions are to be considered: How radical is the change? How great is the need for the computerized techniques? How much uncertainty is there regarding implementation? The answers to these questions will influence the course of the change process and the eventual success or failure of automatization. Many of the basic components of change are simple and obvious. However, it is also quite obvious that they often are overlooked or forgotten by those attempting implementation.

A second important principle for installing technology is that the readiness of the mental health organization to adopt an automated system must be determined. No formal instrument for measuring readiness for automation is currently available. However, relevant questions can be designed by using any of the change models currently in the literature. Table 1 illustrates possible categories that pertain to automation readiness according to Davis' (1971) A VICTORY model of change factors. Mental health practioners considering computerization may use this guide to design questions relevant to their organization. The advantage of this systematic approach to assessing readiness is that it directs attention to the multiple factors necessary for change.

The third principle derived from the automation experiences of others and the change literature requires that the project director have a planned strategy for implementing an automated system. It is well documented that planned change can relieve the stress commonly associated with the process. It would be naive to assume that any strategy eliminates all stress; hence, a change plan must include provisions for dealing with resistance. Several change strategies and information about their use are provided by Zaltman and Duncan (1977). From their review, it is apparent that each strategy has unique characteristics and is appropriate for different situations. The facilitative approach, if used alone, requires that the staff recognize the problem, agree that action is necessary, be open to external aid, and be willing to engage in sclf-help. The
Table 1

A VICTORY Dimensions for Organizational

Readiness for Automation

Cate-

gory

Ability

1 Emergence of a system's advocate, that is, someone who identifies the need for an automated system and will work to push it through.

2 Power base of the organization is supportive of implementation.

3 Availability of resources for automation.

Values 4 Administrative support and cooperation.

5 Attitudes and beliefs of clinicians toward automation.

6 Organizational and administrative style.

7 Organization's flexibility and openness to change.

Information 8 Availability of appropriate computer programs or computer science. expertise.

9 Presence of comparable manual system.

Circumstances 10 A climate of trust is evidential the organization and communication are facilitated.

Timing High priority is being given to the automation project.

Obligation

12 Sources of motivation are present, internal and/or external, for automation.

Resistance 13 Fears of confidentiality, performance appraisal, and mechanization. Expected negative consequences of automation.

Yield

14 Clinical staff and administration foresee the benefits of automation.

reeducational strategies are most effective when a strong commitment to change is not evident and when the change does not have to occur in a short period of time. Persuasive strategies are suggested when a problem in the existing system is not recognized or is not considered to be of major signiificance, or when a solution, such as automation, is not perceived as a legitimate option. Power strategies are recommended when the perceived or felt need for change is very low, the staff commitment to the project is low, and the time frame for completing the change is limited. Power strategies also require the ability to allocate rewards and sanctions (Zaltman \& Duncan, 1977).

Mental health practitioners are most likely to be effective in implementing an automated system if a combination of two or more strategies is used, but the tactics of these approaches overlap and are difficult to conceptualize. During our retrospective analyses of previous systems, we used numerous questions designed to tap each of the four strategies. Sample questions from our implementation survey are presented in Table 2. These examples may serve as a reference for practitioners wishing to understand their organization's 
Table 2

Sample Questions for Surveying Change Strategies Used During Implementation Processes

Power/Coercion

- Were top administrators used effectively before and during the implementation process?

- Was the administrative staff well educated about computer approaches?

- Was the chief administrator prepared for resistance to change prior to the implementation process?

- Would the chief administrator have penalized a clinical employee who failed to cooperate with the needs of the automated system?

Persuasion

- Were clinical staff involved in all stages of the design and implementation process?

- Were there full-time liaison staff members to work with clinicians?

- Were computer science trained personnel carefully exposed to mental health concepts prior to beginning work on the project?

- Were clinician opinion leaders identified and involved in the installation of the computer system?

\section{Reeducation}

- Were numerous meetings and workshops held between the clinical and project staff?

- Were key clinicians given training in da ta processing?

- Were clinicians sent to other facilities with automated systems for purposes of education?

-Was a computer project staff member assigned responsibility for clinician education?

\section{Facilitation}

- Was the project given adequate financial support?

- Did the design of the system attempt to minimize organizational change?

- Were chief administra tors supporting the project?

- Were additional staff provided to allow sufficient clinical and project staff involvement during implementation?

Table 3

Sample Questions for Surveying Strategies for Overcoming Resistance

- Did project staff set forth a formal program for overcoming possible resistance at the beginning of the implementation process?

- Were project directors skilled in change technology?

- Did staff attempt to create an atmosphere that was ready for change?

- Did project staff consider the problem of change acceptance in their design work?

- Were project staff assigned to work with specific opinion leaders?

- Did clinical staff perceive any personnel benefit to accrue from the automated system?

-Were precise implementation goals set?

- Was the system's output designed with clinicians' needs in mind?

- Were the previous data collection habits of clinicians thoroughly understood?

- Was the implementation process timed correctly?

- Was the system planned to give staff rapid feedback?

- Did systems implementation begin where there was a perceived organizational weakness? approach to change or to develop a specific change strategy of their own. Once again, the value of such an analysis is process clarification, a precursor to effective change.

The final principle for those thinking of implementing a computer system is to plan for and understand the meaning of resistance. Promotors of change should search for the causes of resistance and then actively work to reduce or eliminate those causes. The universality of the problem of resistance is clear from the numerous tactics prescribed in the literature for overcoming it. An effective change strategy predicts and plans for resistance before implementation proceeds. In this way, certain resistances are altogether avoided, and others are effectively handled as they arise. In assessing whether an organization has prepared for resistance, numerous questions may be asked. Table 3 represents several sample questions designed to tap key factors for overcoming resistance. Resistance must be attended to; however, it should not be regarded merely as a nuisance. Rather, resistance reflects the nature of the change process and, hence, provides the implementer with a valuable evaluation tool.

In this paper, we have touched lightly on the wealth of literature surrounding change and on the experiences of others implementing automated systems. It is our strong contention that future attempts to introduce computers into the mental health field will prove more successful if principles from change technology, such as those discussed above, are incorporated into the process.

\section{REFERENCE NOTES}

1. Hedlund, J. L. Clinical computer applications: Acceptance and utilization. Paper presented to the 24th Institute on Hospital and Community Psychiatry, St. Louis, Mo., 1972.

2. Sletten, I., \& Hedlund, J. L. The Missouri automated standard system of psychiatry: Current status, special problems, and future plans. Paper presented at the symposium "Progress in Psychiatric Information Systems," Washington, D.C., 1973.

3. Burwell, B. A., \& Chavern, H. E. Steps to accountability. Paper presented at the Workshop on Management Information Systems, Region VII Annual Meeting, Rapid City, S.D., 1978.

4. Sorensen, J. E., \& Hanbery, G. W. Developing information systems for mental health organizations Paper presented at the Technical Assistance Workshop, Chicago, Ill., 1976.

\section{REFERENCES}

Bennett, C. L., \& Gruenberg, E. A substitute for clinical thinking? International Journal of Psychiatry, 1970, 9, 621-627.

Bennett, w. L., \& HoucK, J. A three step plan for automation. Hospital, 1967, 41, 61-66.

Brewer, R. S., Amerss, A. P., Thompson, W. A., \& Wood, H. E. Waiters for the data base. Journal of Systems Management, 1972, 23, 32-34.

Cole, E. B., Johnson, J. H., \& Williams, T. A. Design considerations for an on-line computer system for automated psychiatric assessment. Behavior Research Methods \& Instrumentation, 1975, 7, 199-200. 
DAvis, H. R. A checklist for change. In National Institute of Mental Health (Ed.), A manual for research utilization. Washington, D.C: U.S. Government Printing Office, 1971.

Davis, H. R., \& SAlasin, S. E. The utilization of evaluation. In E. L. Struening \& M. Gultentag (Eds.), Handbook of evaluation research. Beverly Hills, Calif: Sage, 1975.

Dow, J. T. Designing computer software for information systems in psychiatry. Computers and Biomedical Research, 1975, 8, 538-559.

Elpers, J. R., \& Chapman, R. L. Management information for mental health services. Administration in Mental Health, 1973, Fall, 12-25.

Freil, P. B., Reznikoff, M., \& Rosenberg, M. Attitudes toward computers among nursing personnel in a general hospital. Connecticut Medicine, 1969, 33, 307-308.

Glaser, E. M. Knowledge transfer and institutional change. Professional Psychology, 1973, 4, 434-444.

Glueck, B. C. Automation and social change. Comprehensive Psychiatry, 1967, 8, 441-449.

Graetz, R. E. The computer-A new tool for psychiatry. Hospital and Community Psychiatry, 1966, 17, 26-34.

Grossman, J. H., Barnett, G. O., McGuire, M. T., \& SwedLow, D. B. Evaluation of computer-acquired patient histories. Journal of the American Medical Association, 1971, 215, 1286-1291.

Heduund, J. L. Critical issues in clinicians' acceptance and use of computer systems. Hospital and Community Psychiatry, 1974, 25, 103-104.

Hedlund, J. L., Sletten, I., Evenson, R., Altman, H., \& Cно, D. W. Automated psychiatric information systems: A critical review of Missouri's Standard System of Psychiatry (SSOP). Journal of Operational Psychiatry, 1977, 8, 5-26.

Human Interaction Regearch InstTtute/National Institute of Mental Health. Putting knowledge to use: $A$ distillation of the literature regarding knowledge transfer and change. Los Angeles, Calif: Human Interaction Research Institute, 1976.

JoHnson, J. H. A practical guide to installing a computer system in a mental health setting. In J. B. Sidowski, J. H. Johnson, \& T. A. Williams (Eds.), Technology in mental health care delivery systems. Norwood, N.J: Ablex, 1980.

Johnson, J. H., Williams, T. A., Giannetti, R. A., Klinglen, D. E., \& Naxashima, B. R. Organizational preparedness for change: Staff acceptance of an on-line computer assisted assessment system. Behavior Research Methods \& Instrumentation, 1978, 10, 186-190.

Kınesux, T. S., DAvis, H., \& Lund, S. H. Knowledge utilization and planned change in the mental health services. In J. B. Sidowski, J. H. Johnson, \& T. A. Williams, (Eds.), Technology in mental health care delivery systems. Norwood, N.J: Ablex, 1980.

Klein, M. H., Greist, J. H., \& VanCura, L. J. Computers and psychiatry. Archives of General Psychiatry, 1975, 32, 837-843.

Klinaler, D. E., Johnson, J. H., \& Williams, T. A. Strategies in the evaluation of an on-line computer-assisted unit for intake assessment of mental health patients. Behavior Research Methods \& Instrumentation, 1976, 8, 95-100.

Klingler, D. E., Miller, D. A., Johnson, J. H., \& Williams, T. A. Process evaluation of an on-line computer-assisted unit for intake assessment of mental health patients. Behavior Research Methods \& Instrumentation, 1977, 9, 110-116.

Kotter, P. The elements of social action. In G. Zaltman (Ed.) Processes and phenomena of social change. New York: Wiley, 1973.

Landau, B., \& WiLks, C. Development of an automated data system for the psychiatric service of the juvenile and family court. In B. Willer, G. H. Miller, \& L. Cantrell (Eds.), Information and feedback for evaluation. Toronto: Communications Department, York University, 1975.

Laska, E., Logemann, G., Weinstein, A., \& Bank, R. The ideal system. International Journal of Psychiatry, 1970, 9, 637-640.

LEADER, M. A., \& KLEIN, D. F. Reflections on instituting a computerized psychosocial history in a clinical facility. Comprehensive Psychiatry, 1977, 5, 489-496.

MurRaY, G. R., \& KLAiner, L. M. On making systems analysis results operational in comprehensive health planning. American Journal of Public Health, 1972, 63, 980-984.

Rosenberg, M., \& Ericson, R. P. The clinician and the computer-Affair, marriage, or divorce. American Journal of Psychiatry, 1969, 1, 28-32.

St. Clair, C., Siegel, J., Caruso, R., \& Spivack, G. Computerizing a mental health center information system. Mental Health, 1976, 4, 10-18.

Watson, G. Resistance to change. In G. Zaltman (Ed). Processes and phenomenon of social change. New York: Wiley, 1973.

Znltuan, G. Processes and phenomena of social change. New York: Wiley, 1973.

Zaltman, G., \& Duncan, R. Strategies for planned change. New York: Wiley, 1977.

Zalman, G., DuncaN, R., \& Holbek, J. Innovations and organizations. New York: Wiley, 1973. 